ISSN 1991- 8690

website: http://jsci.utq.edu.iq

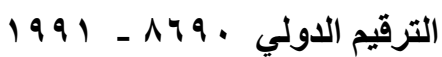

Email: utjsci@utq.edu.iq

\title{
Diffraction Efficiency In Case Of Small-Angle for Bragg Diffraction
}

\author{
Haider Kadhim Muhammad \\ Thi-Qar Univ.- College of Science- Department of Physics
}

\begin{abstract}
The diffraction efficiency of small- angle Bragg diffraction for three crystals different properties (KRS5, PbMo02, and LiNb03) has been investigated, respectively. The results have shown that, the change in the magnitude of diffraction efficiency by acoustic intensity ( $I_{\text {acoustic }}$ ) depends on the properties of the crystal used, especially, the relative figure of merit of the material $\left(\mathrm{M}_{w}\right)$.

The maximum values of diffraction efficiency in case of the three crystals (KRS5, PbMo02, and LiNb03) have exactly been obtained at acoustic intensity ( $I_{\text {acoustic }}$ ) of values $\left(I_{\text {acoustic }}=\mathbf{0 . 7}, \mathbf{5}, \mathbf{1 0 0}\right) \frac{\mathrm{w}}{(\mathrm{mm})^{2}}$ respectively. So it has been possible to control diffraction efficiency by the intensity of acoustic wave $\left(I_{\text {acoustic }}\right)$.
\end{abstract}

\section{Introduction}

Acousto-optics interaction occurs in all optical medium when an acoustic wave and optical been are present in the medium. In general when an acoustic wave launched into the optical medium, its generates a refractive index wave that behaves like sinusoidal grating, the acousto-optics effects a specific case as photoelasticity, where is a change of materials permittivity mechanical strain $\left(a_{j}\right)$. Photo elasticity is the variation of the optical indicartix coefficient $\left(B_{i}\right)$ caused by the strain $\left(a_{j}\right)$ given as follows $[1,2]$ :

$$
\left(\Delta B_{i}=\left(\frac{1}{n^{2}}\right)_{i j}=\mathrm{P}_{i j} a_{j}\right)
$$

Where $\left(\mathrm{P}_{i j}\right)$ is the photo elastic tensor with component, $(i, j)=1,2 \ldots, 6$. The strain $\left(a_{j}\right)$ is a result of acoustic wave which has been excited with in a transparent medium. This 
gives rise to the variation of refractive index $n(Z, t)$, for acoustic wave propagating along $\mathrm{Z}$ axis. So the change in refractive index can be expressed as [1-3].

$$
n(Z, t)=n+\Delta n \operatorname{Sin}(K Z-\Omega t+\phi) .
$$

Where $\Omega$ is the frequency of acoustic wave.

An incident optical beam passing through this grating will diffract into several orders as (Raman-Nath) or into only two orders zeroth and first order (A0, $\left.A_{1}\right)$, respectively. This has been called Bragg diffraction pattern dependent on the (KleinCook parameter $\mathrm{Q}) \mathrm{Q}<<1$ or $\mathrm{Q}>>1$ respectively [4].

However, there is number of cases in which the interaction configuration requires that the mode amplitudes $\left(\mathrm{A}_{0}, \mathrm{~A}_{1}\right)$ be functions of either $\mathrm{x}$ or $\mathrm{z}$ only, therefore the acousto-optics in Bragg interaction divided in two interaction configuration, for low sound frequency (small angle diffraction) shown in fig.(1a) and high frequencies (large angle diffraction) shown in fig.(1b). In the small angle Bragg diffraction the amplitudes (A0, A1) are functions of $\mathrm{x}$ axis as required by the boundary conditions $[1,5,6]$.

In present work, we discuss the diffraction efficiency for light diffracted from ultrasound in case of small-angle for Bragg diffraction.

\section{Theory Part}

When the angle between the direction of propagation of the light and the acoustic wavefornt is small the interaction length $\mathrm{L}$ is the width of the acoustic beam. thus, the amplitude A 0 and A1 are function of $x$ only, because $\mathrm{x}$ measures the depth of penetration in this interaction configuration one can see fig.(1). The coupled equations which describe the amplitudes in special case of a single wave incident at $\mathrm{x}=0(\mathrm{~A} 0(0)=0)$ [7-9].

$$
\begin{aligned}
& A_{0}(x)=A_{0}(0) \operatorname{Cos} \gamma x \\
& A_{1}(x)=-i \frac{\gamma}{|\gamma|} A_{0}(0) \operatorname{Sin} \gamma x
\end{aligned}
$$

Where: $\gamma$ is the coupling constant giving by the following relation:

$$
\gamma=\frac{\omega n^{3}}{4 c \operatorname{Cos} \theta_{B}}\left|P_{1} \cdot(\mathrm{P} a) P_{2}\right|
$$

Where $(\mathrm{Pa})$ is the matrix formed by the element of the strain component and the photoelastic coefficients $\left(\mathrm{P}_{i j} a_{j}\right), \omega$ the frequency of light beam incident, $P_{12}$ is the unit vectors representing the polarization state of the incident and diffracted light.

The total mode power carried by both light waves is conserved [2,6].If the interaction distance (L) between the two beams is $\gamma L=\frac{1}{2} \pi$, the total power of incident beam is transferred into the diffracted light (A1 first order), using eq.(1) $[1,5,7,8]$.

$$
\frac{I_{1}}{I_{0}}=\frac{\left|A_{1}(L)\right|^{2}}{\left|A_{0}(0)\right|^{2}}=\operatorname{Sin}^{2} \gamma L
$$


Since the strain component $(a)$ associated with the sound wave is directly related to the acoustic intensity ( $I_{\text {acoustic }}$ ) of the sound, it is convenient to express the diffraction efficiency as in eq. (3) in term of $\left(I_{\text {acoustic }}\right)$.so, at minimum values of Bragg angle the coupling constant is given by the following relation:

$$
\gamma=\frac{\omega n^{3}}{4 c} \overline{\mathrm{P}} \bar{a}
$$

Where $\overline{\mathrm{P}}$ are the effective photoelastic coefficients, $\bar{a}$ is the effective strain component, (n) the refraction index of the interaction medium.

The acoustic intensity is written by:

$$
I_{\text {acoustic }}=\frac{1}{2} \rho v^{3} \bar{a}^{2}
$$

Where: $v$ is the velocity phase and $\rho$ is the mass intensity.

From eq.(5) we note that $\bar{a}$ is proportional to the square root of the $I_{\text {acoustic }}$ in same time it proportional with coupling constant $\gamma$ eq.(4) ,therefore, it is convenient to define a figure merit of diffraction as follows $[4,10]$.

$$
\mathrm{M}=\frac{n^{6} \bar{P}^{2}}{\rho v^{3}}
$$

By using eq. $(4,5,6)$, the eq.(3) becomes.

$$
\frac{I_{d}}{I_{i}}=\operatorname{Sin}^{2}\left(\frac{\pi L}{\sqrt{2} \lambda} \sqrt{\mathrm{MI}}\right)
$$

Now, one can consider the propagation of a sound wave in water, assuming that both the incident and diffracted light waves are polarized to the plane of incident (xz) .The constant of water as acousto-optics medium from[8,9]is given:

$$
\mathrm{n}=1.33 \quad, \overline{\mathrm{P}}=0.31 \quad, v=1.5 * 10^{3} \frac{\mathrm{m}}{\mathrm{s}} \quad, \rho=1000 \frac{\mathrm{kg}}{\mathrm{m}^{3}}, \quad \lambda=0.6238 \mu \mathrm{m}
$$

Substituting this data in eqs. $(6,7)$ we have obtained .

$$
\left(\frac{I_{d}}{I_{i}}\right)_{H 2 o}=\operatorname{Sin}^{2}\left(1.4 L \sqrt{I_{a}}\right)
$$

One can combine the two eqs. $(7,8)$ for other materials at other wavelengths.

$$
\frac{I_{d}}{I_{i}}=\operatorname{Sin}^{2}\left(1.4 \frac{0.6328}{\lambda(\mu m)} L \sqrt{\mathrm{M}_{w} I_{a}}\right)
$$

Where: $M_{w}=\frac{M_{\text {material }}}{M_{\text {water }}}$ is the diffraction of figure merit of material relative to figure merit of water. 


\section{$\underline{\text { Results and discussion }}$}

The relative fraction intensity of the light diffracted by ultrasound wave determined to three different materials, commonly used in the acousto-optics interaction are (KRS5, PbMo02 and LiNb03). Figures (2, 3, and 4) show the diffraction efficiency as a function of acoustic intensity $I_{\text {acoustic }}$ for the three materials respectively.

We observe clearly the growth of diffraction efficiency curve is proportional to the intensity of acoustic wave to get a maximum value but with different value of acoustic intensity $I_{a}$, corresponding the properties of interaction medium.

The maximum efficiency as shown in fig.(2) appears at low value of $I_{\text {acoustic }}$, and exactly it is equal to $\left(I_{\text {acoustic }}=0.7 \frac{\mathrm{w}}{(\mathrm{mm})^{2}}\right.$ ) that is to say the range of reaching to maximum efficiency takes place in small value of acoustic intensity $I_{a}$, then it decreases in small range of $I_{\text {acoustic }}$ as well.

On the other hand, from fig.(3) the maximum efficiency appears at a value equals to ( $I_{\text {acoustic }}=5 \frac{w}{(\mathrm{~mm})^{2}}$ ) which is larger than the value obtained from fig.(2), comparing between the two materials (KRS5 fg.(2),PbM0O3 fg.(3))respectively.

It is remarkable from fig.(4), the peak of diffraction efficiency occurs at high value of acoustic intensity exactly $\left(I_{\text {acoustic }}=100 \frac{\mathrm{w}}{(\mathrm{mm})^{2}}\right.$ ), this value is very large comparing with the last values in fig. $(2,3)$ respectively, then this value decreases with high range of $I_{\text {acoustic }}$ again.

As stated above, one can note in very small values of $I_{\text {acoustic }}$ the diffracted light intensity can be observed, that means a complete exchange of energy between the incident light which represent the transmitted light (zero order of amplitude A0) and diffracted light which represent (first order of amplitude A1) in Bragg diffraction pattern as shown in fig. (1), is taking place at range of acoustic wave which is depending on the type and properties of the crystal like (optical wave polarization and direction, $\mathrm{n}$ the index of refraction, $\rho$ the density, $\overline{\mathrm{P}}$ the effective photoelastic constant and $v$ is the velocity phase etc.).

\section{Conclusions}

We have applied the formula which describes the diffraction efficiency as in eq. (9) to three materials commonly used in acousto-optics interaction (KRS5, PbMo02, and LiNb03) respectively. The efficiency versus acoustic intensity $I_{\text {acoustic }}$ occurs at limited intensity range depending on the properties of interaction medium. According to a range of $I_{\text {acoustic }}$ which is used to obtain the efficiency at low frequency of an acoustic wave, knowing that $I_{\text {acoustic }} \alpha \Omega^{3}$. 


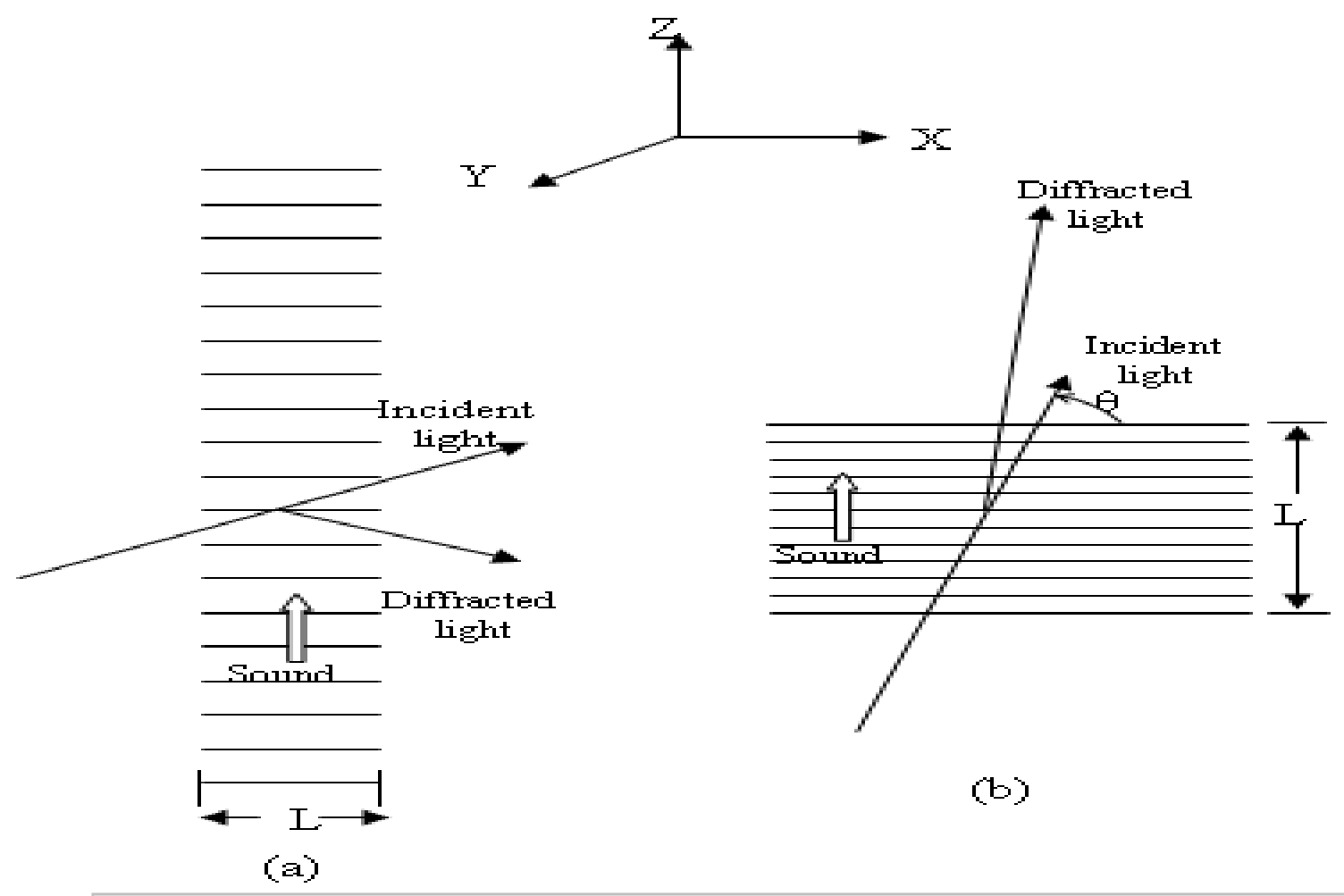

Fig. (1) Tow common interaction configuration:

(a)Small-Bragg angle diffraction

(b)Large- Bragg angle diffraction

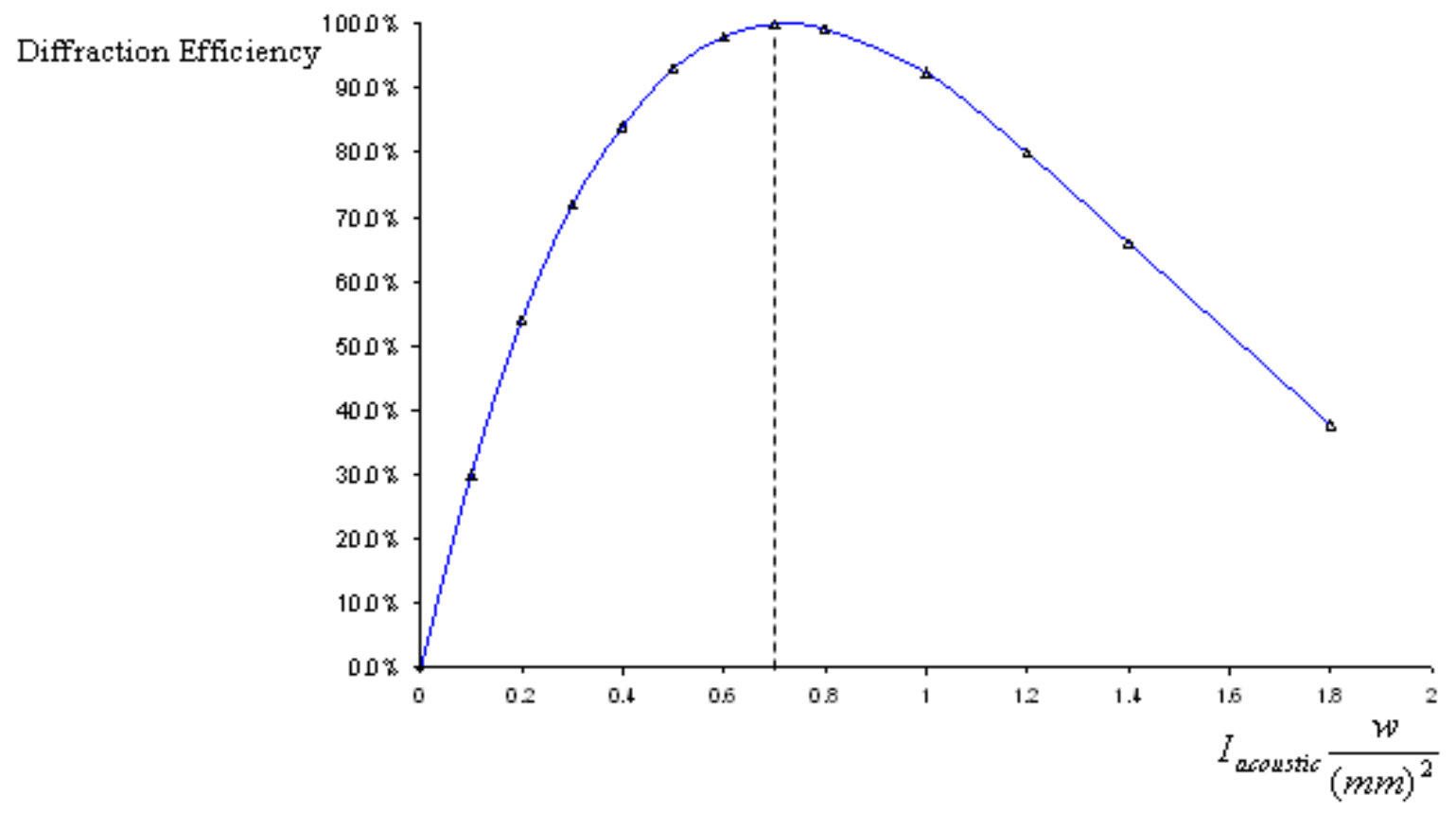

Fig.(2) Plot of diffraction efficiency versus acoustic intensity ( $I_{\text {acoustic }}$ )

for (KRS5). $\mathrm{M}_{w}=1.6[1]$ 


\section{J.Thi-Qar Sci. $\quad$ Vol.2 (1)}

Jan./2009

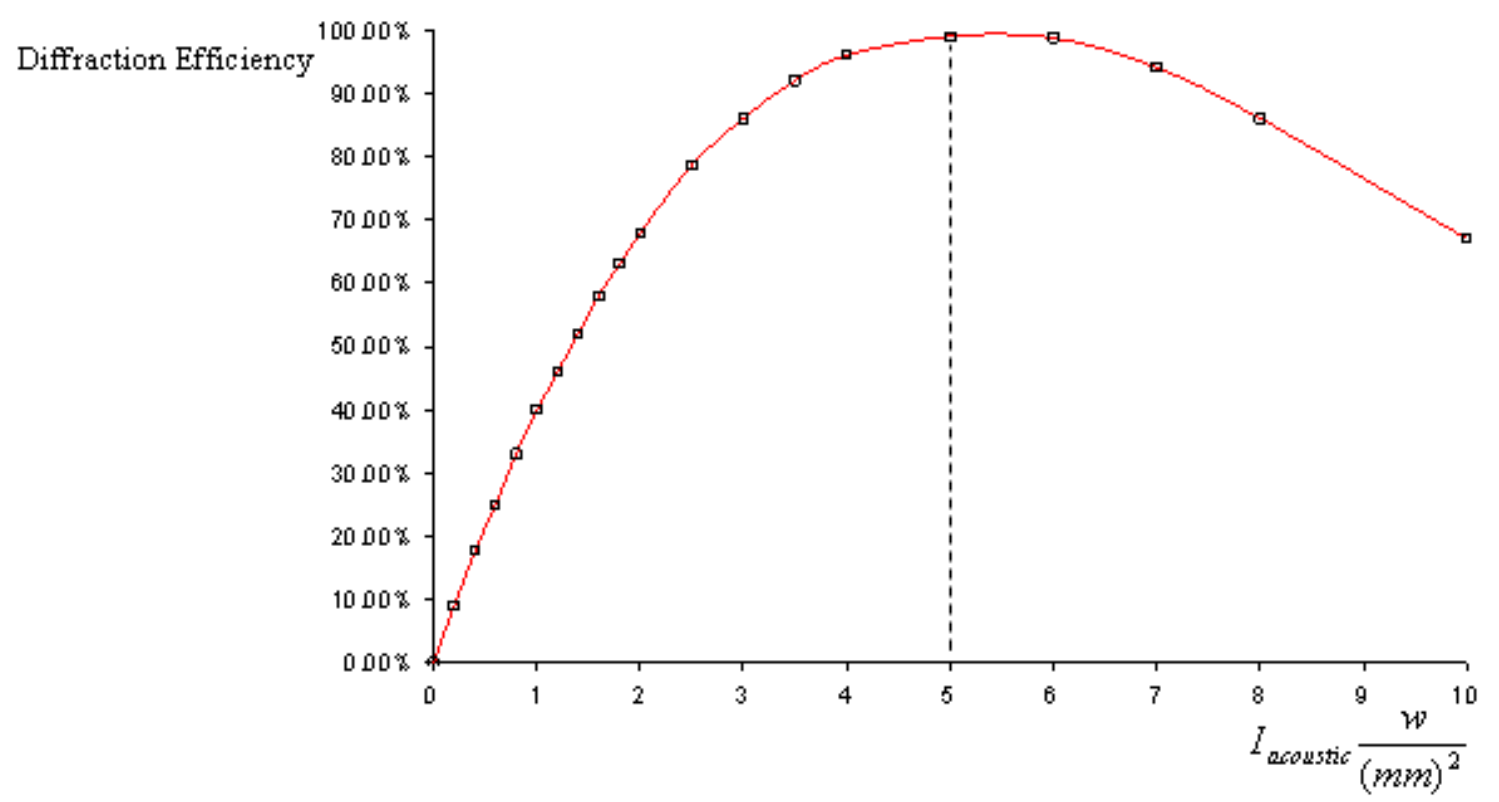

Fig.(3) Plot of diffraction efficiency versus acoustic intensity $\left(I_{\text {acoustic }}\right)$ for $(\mathbf{P b M o O 2}) . \mathrm{M}_{w}=0.22[1]$

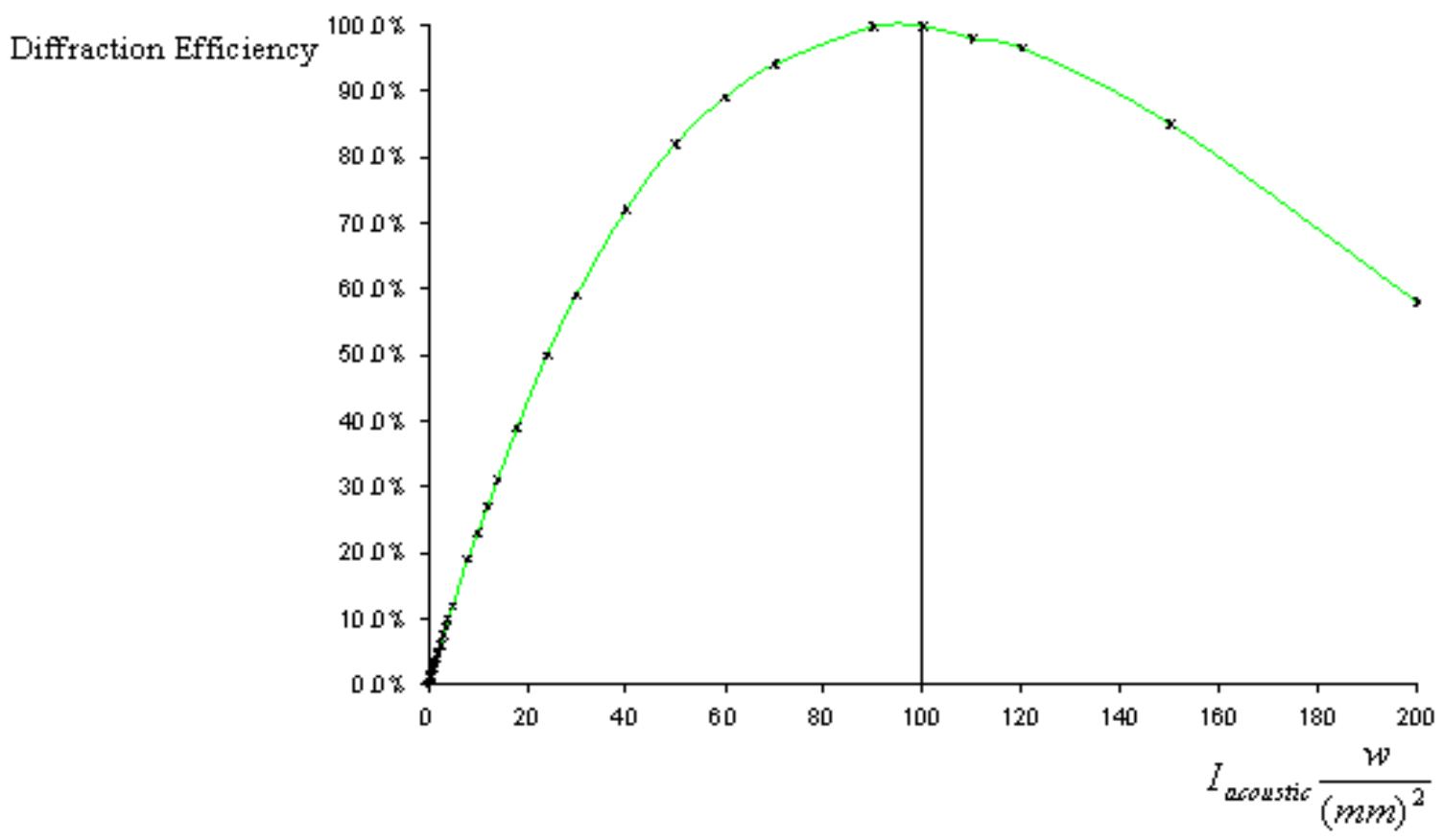

Fig. (4) Plot of diffraction efficiency versus acoustic intensity ( $I_{\text {acoustic }}$ ) for $(\mathrm{LiNbO3}) . \mathrm{M}_{w}=0.012[1]$ 


\section{REFERENCES}

[1] Yariv A and Yeh P, 1984 "Optical Waves in Crystals" Wiley, New York.

[2] Muhammad H.K., 2005,"The Amplitude and Phase in collinear Acousto-Optics interactions".Thesis in M.Sc., Al-Mustansiriyah Unv.

[3] S.M. Kolomiets, 2003 " Sound velocity in transparent medium measurement by acousto-optic. Methods" XIII Session of the Russian Acoustical society, Aug. 25-29 Moscow.

[4] "Introduction to acousto-optics" http://www.Brimrose.com

[5] Zadorin A.S., December, 1982 "Bragg acousto-optical interaction in crystal media" Russian. Physics journal, Vol.25,(12).

[6] Ptrov V.V., Lapin S.A. 2003" High Frequency in Bragg Cell AcoustoOptics"September, Saratov State University, Saratov Russia.

[7] Zyuryukin Yu.A., 2001 "Method of coupled waves in the theory of diffraction of light by elastic .Waves crystals" Russian physics journal, Vol.44, (10).

[8] Lean E.G., Dakss M.L., Powell C.G., 1969,"Efficiiencies and Bandwidths of Intracavity . Acousto-optics Devices ", IBM Jou.

[9] Nayak r., et al, 1999,"Studies on acousto-optical interaction in SrTiO3/BaTiO3/SrTiO3 epitaxail . Thin film" J. Phys. D: Appl. Phys. 32.

[10] Muhammad H.K., 2008, "Investigation Phase In Case Of Bragg Coupling ", Thi-Qar, J., Vol.4, (2).

$$
\begin{aligned}
& \text { الخلاصة } \\
& \text { في هذه الاراسة تم البحث في كفاءة الحيود لحالة حيود برائ (زاوية حيود صغيرة) ولثلاث بلورات } \\
& \text { مختلفة الخصائص (KRS5, PbMo02, and LiNb03) على التو الي. } \\
& \text { التتائج بينت إن التغير في قيمة كفاءة الحيود بواسطة الثدة الصوتية) I I I تعتمد على صفات } \\
& \text { البلورة المستخدمة وخصوصا النوعية السمعية ـالبصرية النسبية للوسط) ( }
\end{aligned}
$$

إن أقصى قيمة لكفاءة الحيود تم الحصول عليها للبلورات الثلاث (KRS5, PbMo02, and LiNb03)

عثد قيم محدة تماما لثدة الموجة الصوتية هي

$$
\text { أصبع من السهل التحكم بكفاعة الحيود بواسطة شدة الموجة الصوتية) }
$$

